\title{
Correction to: Lion and Man Game in Compact Spaces
}

\author{
Olga Yufereva ${ }^{1,2}$ (D)
}

Published online: 13 October 2018

○ Springer Science+Business Media, LLC, part of Springer Nature 2018

\section{Correction to: Dyn Games Appl https://doi.org/10.1007/s13235-018-0239-9}

The original version of this article unfortunately contained a mistake in the author name. The given name and the family name have been interchanged. The author name should be Olga Yufereva instead of Yufereva Olga.

The original article has been corrected.

The original article can be found online at https://doi.org/10.1007/s13235-018-0239-9.

$\bowtie$ Olga Yufereva

yufereva12@gmail.com

1 Krasovskii Institute of Mathematics and Mechanics UrB RAS, 16, Kovalevskoy str., Ekaterinburg, Russia 620990

2 Chair of Applied Mathematics and Mechanics, Institute of Mathematics and Computer Science, Ural Federal University, 4, Turgeneva str., Ekaterinburg, Russia 620083 